\title{
Calcium Channel Binding
}

National Cancer Institute

\section{Source}

National Cancer Institute. Calcium Channel Binding. NCI Thesaurus. Code C40481.

A process that involves the binding of a cognate lig and to a member of the calcium

channel receptor family. These interactions are involved in the release of calcium from intracellular stores. 